\title{
A COMPARISON BETWEEN I-GEL AND THE LMA CLASSIC IN SPONTANEOUSLY VENTILATING ANAESTHETISED PATIENTS
}

(Major) Vishal Arora1, Shivani Fotedar², Mohd. Zafeer Khan³, Gunjan Awasthi', Arvind Kumar Arya ${ }^{5}$, Vivek Singh ${ }^{6}$

${ }^{1}$ Associate Professor, Department of Anaesthesiology, Saraswati Medical College, UNNAO.

${ }^{2}$ Senior Resident, Department of Anaesthesiology, Institute of Human Behaviour and Allied Sciences, New Delhi.

${ }^{3}$ Assistant Professor, Department of Anaesthesiology, Era's Lucknow Medical College.

${ }^{4}$ Senior Resident, Department of Anaesthesiology, KGMU, Lucknow.

${ }_{5}^{5}$ Assistant Professor, Department of Neuroanaesthesia, Institute of Human Behaviour and Allied Sciences, New Delhi.

${ }^{6}$ Assistant Professor, Department of Anaesthesiology, GCRG Institute of Medical Sciences, Lucknow.

\section{ABSTRACT}

\section{BACKGROUND}

Supraglottic airway devices (SAD) are now widely used for surgeries requiring general anaesthesia. They also have a role in airway management for resuscitation as first responder devices, rescue devices or for their use during patient extraction. The aim of this study is to compare the LMA classic and the i-gel, over varied parameters and establish the superior supraglottic airway device amongst the two.

\section{MATERIALS AND METHODS}

Patients were induced and i-gel or c-LMA was inserted without any muscle relaxation. Time to insert, no. of attempts taken, vitals and post-operative complications were recorded.

Statistical Analysis Used- Unpaired Student's ' $\mathrm{t}$ ' test and ' $\mathrm{z}$ ' test.

Settings and Design- This was a randomised controlled trial and single-blinded study conducted on 80 patients divided in 2 groups viz. i-gel and c-LMA.

\section{RESULTS}

The i-gel takes a lesser amount of time for insertion as compared to the LMA classic and is easier also. No complications were noted with i-gel. The i-gel is a superior supraglottic airway device as compared to c-LMA.

\section{CONCLUSION}

The i-gel appears to be a better supraglottic airway device as compared to the LMA classic.

\section{KEYWORDS}

LMA, i-gel, Anaesthesia, Spontaneous Ventilation.

HOW TO CITE THIS ARTICLE: Arora V, Fotedar S, Khan MZ, et al. A comparison between the i-gel and the LMA classic in spontaneously ventilating anaesthetised patients. J. Evolution Med. Dent. Sci. 2018;7(08):1034-1039, DOI: $10.14260 /$ jemds/2018/236

\section{BACKGROUND}

Securing airway during administration of Anaesthesia is of vital importance and significant urgency, wherein lapses can lead to catastrophic outcomes. Traditionally, this has been accomplished by either bag and mask ventilation or through placement of endotracheal tube (ETT) followed by ventilation. In extreme emergencies and unskilled hands, mouth to mouth respiration during resuscitation has also been recommended. Each of these methods has its own difficulties, hazards and at times unacceptable outcomes.1,2 Supraglottic airway devices (SAD) are now widely used for surgeries requiring general anaesthesia. They also have a role in airway management for resuscitation as first responder devices, rescue devices or for their use during patient extraction. The Difficult Airway Society and the ILCOR have also included the SADs in their algorithm.3,4

'Financial or Other Competing Interest': None.

Submission 15-07-2017, Peer Review 01-02-2018,

Acceptance 08-02-2018, Published 19-02-2018.

Corresponding Author:

Dr. (Major) Vishal Arora,

Wisdom Academy, Urmilapuri, Kamta,

Lucknow-226028, U. P.

E-mail: arovish1974@gmail.com

DOI: $10.14260 /$ jemds $/ 2018 / 236$

In order to understand them the SADs can be classified in two broad ways, either on the basis of presence or absence of an inflatable cuff or as first generation and second generation SADs. ${ }^{5}$ Though different SADs have been mutually compared on various parameters, comparison between the LMA classic and the i-gel in terms of their performance and better suitability amongst spontaneously breathing adult patients has not been investigated enough. Besides, there are hardly any studies on Indian subjects and in Indian settings considering the different racial and anthropometric attributes of ethnic Indian population. Thus, there is ample reason to undertake another study, comparing the clinical performance and ease of insertion of the devices.6,7 This study intends to compare the two devices.

\section{Aims and Objectives}

To compare the LMA classic and the i-gel over varied parameters, and establish the superior supraglottic airway device amongst the two.2,8,4

\section{Objectives}

To Compare the Function of the i-gel and Classic LMA under the Following Headings

- Ease of insertion of the device (Assessed by the duration taken to insert the device). 
- Number of attempts taken to insert the device.

- Haemodynamic changes on inserting and after inserting the device.

- Post-operative complications (procedure related complications) if any to be recorded.2,8,4

\section{MATERIALS AND METHODS}

This was a randomised controlled trial and single-blinded study. After obtaining Ethical Committee approval, a sample size of 80 patients was decided to conduct the study. The randomisation was done on a computer-generated lottery method.

\section{Sample Size Estimation}

$\mathrm{N}=\left(\sigma_{1}^{2}+\sigma_{2}^{2}\right)\left(\mathrm{Z}_{\alpha}+\mathrm{Z}_{\beta}\right)^{2} / \mathrm{d}^{2}$

$\sigma_{1}=0.1$

$\sigma_{2}=0.5$

$\mathrm{d}=\operatorname{mean}\left(\sigma_{1}, \sigma_{2}\right)=47.4$

Type I error $\alpha=5 \%$

Type II error $\beta=10 \%$

Power of study $=90 \%$

The sample size comes out to be $\mathrm{n}=45+10 \%$ data loss $=40$ in each group.

\section{Inclusion Criteria}

Patients belonging to age groups between 20 - 60 years, ASA grade 1 or 2 , MP grade 1 or 2 with surgeries not lasting for more than an hour were selected for the study.

\section{Exclusion Criteria}

Full stomach patients, caesarean sections, emergent surgeries, a BMI of less than 20 or more 28 or patients unwilling to enrol for the study.

Prior to the day of surgery, the patients were visited as per the pre-anaesthetic check protocol.

A fully informed consent was taken. Pre-medication with Tab. Diazepam $5 \mathrm{mg}$ was given, and patients were advised to stay nil per oral till the morning of surgery. On arrival in the operation theatre, the patient was made to lie supine. Multiparameter monitors were attached and all the baseline parameters (NIBP, SpO2, ECG, EtCO2 and Heart Rate) were recorded.

Patients were pre-oxygenated for 3 minutes with 100\% oxygen followed by Inj. midazolam $2 \mathrm{mg}$ IV, Inj. Glycopyrrolate $0.01 \mathrm{mg} / \mathrm{kg}$ IV, Inj. Ondansetron $0.1 \mathrm{mg} / \mathrm{kg}$ IV and Inj. Fentanyl $2 \mathrm{mcg} / \mathrm{kg}$ IV were also given. Induction was carried out using Injection Propofol $2 \mathrm{mg} / \mathrm{kg}$ IV. The patient was kept on spontaneous ventilation and maintained on Halothane, Oxygen and Nitrous Oxide in titrated MACs. After achieving an adequate depth of anaesthesia, the Supraglottic Airway Device (i-gel or LMA), whichever was chosen was inserted. Time taken for the insertion was recorded. For the c-LMA, the size of the device was decided by the patient's body weight and the manufacturer's recommendation for that particular body weight. For the c-LMA, the standard size chart was used. The standard pre-use test for both the devices was performed, which included inflation and checking of the cuff for the c-LMA along with its structural integrity and colour. For the i-gel it being a reusable device, there are no pre-use tests which were required to be carried out. Both the devices were lubricated on the posterior surface and the tip using a water-based gel (KY jelly), and the classic LMA was partially or fully deflated depending on the operator's convenience, prior to the insertion of the device. ${ }^{1,9}$ The Bain's circuit was attached to the devices connector end. The patient was kept on spontaneous ventilation and adequate concentrations of MAC of Halothane and Nitrous oxide were delivered by the machine. In both the groups, if it were impossible to insert the Supraglottic Airway Device after consecutive attempts, the following manoeuvres were done. A Chin lift in order to open the airway along with a Jaw thrust and a Head extension, or Flexion of the neck was done.

(Chandy Varghese manoeuvre) In case of an i-gel, the position was adjusted by pushing or pulling the device. For cLMA, the cuff was adjusted prior to its inflation or in a semiinflated position. (Bailey manoeuvre) After any manoeuvre, adequacy of ventilation was assessed by auscultating the chest and making sure that there is equal air entry bilaterally. If the insertion of the device failed in a single attempt, then two more attempts were allowed. The procedure was abandoned after failure of the third attempt and the patient was intubated or awakened. This case was henceforth not included in the study group. The heart rate, blood pressure, etCO2 and SpO2 were recorded at the time of insertion and every minute for the first 5 minutes and then every 5 mins till the time the procedure ended.

Oxygen and Nitrous oxide were given for maintenance of anaesthesia, in a 50: 50 ratio along with halothane. No muscle relaxant was used. At the completion of the surgery, the i-gel or the c-LMA was removed after the patient gained consciousness which was observed by resumption of the reflexes of the cornea and eyelash. After the patient's gag reflex resumed, the device was removed. 5 minutes of dedicated post-operative oxygenation was done before shifting the patient to the recovery. Each patient was questioned immediately after removal of the device to determine whether the following complications have occurred or not for the first $24 \mathrm{hrs}$. postoperatively. The complications likely to occur and be noted were sore throat, constant throat pain independent of swallowing action, dysphagia, dysphonia, sore jaw, numbness of tongue or oropharynx, blocked or painful ears, reduced hearing or neck pain. Also, post-extubation cough, breath holding or laryngospasm were also taken into consideration. $1,10,11,12$

\section{Statistical Tools Employed}

The statistical analysis was done using SPSS (Statistical Package for Social Sciences), Version 15.0 Statistical Analysis Software. The values were represented in Number (\%) and Mean \pm SD. Chi-square test, student's ' $t$ ' test and Mann-Whitney $\mathrm{U}$ test were used. $\mathrm{P}<0.05$ was considered significant.

\section{RESULTS}

\begin{tabular}{|c|c|c|c|c|}
\hline \multicolumn{2}{|c|}{ Age } & i-gel (S.D.) & c-LMA (S.D.) & P-value \\
\hline \multicolumn{2}{|c|}{ BMI } & $24.64( \pm 13)$ & $36.85( \pm 13.7)$ & 0.528 \\
\hline \multirow{4}{*}{ Sex } & \multirow{2}{*}{ Male } & $\begin{array}{r}22 \pm 1.3 \\
(55 \%)\end{array}$ & $25.11( \pm 8.9)$ & 0.675 \\
\cline { 2 - 4 } & \multirow{2}{*}{ Female } & $\begin{array}{c}18 \pm 1.5 \\
(40 \%)\end{array}$ & $\begin{array}{c}23 \pm 2.5 \\
(57.5 \%)\end{array}$ & \multirow{2}{*}{0.263} \\
\cline { 2 - 3 } & \multicolumn{3}{|c|}{ Table 1. Demographics } \\
\hline
\end{tabular}




\begin{tabular}{|c|c|c|c|}
\hline Type of Surgery & i-gel & c-LMA & P-value \\
\hline $\begin{array}{l}\text { Minor eye } \\
\text { procedures }\end{array}$ & $2 \pm 0.3(5 \%)$ & $\begin{array}{c}3 \pm \\
1.1(7.5 \%)\end{array}$ & \multirow{6}{*}{0.822} \\
\hline Hernioplasties & $\begin{array}{c}13 \pm 1.2 \\
(32.5 \%)\end{array}$ & $\begin{array}{c}15 \pm \\
3.6(37.5 \%)\end{array}$ & \\
\hline ORIF with TENS & $\begin{array}{l}15 \pm 3.3 \\
(37.5 \%)\end{array}$ & $\begin{array}{c}10 \pm \\
2.9(25 \%)\end{array}$ & \\
\hline $\begin{array}{l}\text { Incision and } \\
\text { Drainage }\end{array}$ & $\begin{array}{c}4 \pm \\
1.2(10 \%)\end{array}$ & $\begin{array}{c} \pm \pm \\
1.1(17.5 \%)\end{array}$ & \\
\hline $\begin{array}{c}\text { Fibroadenoma } \\
\text { Excision }\end{array}$ & $\begin{array}{c}4 \pm \\
1.1(10 \%)\end{array}$ & $\begin{array}{c}5 \pm \\
1.0(12.5 \%)\end{array}$ & \\
\hline $\begin{array}{c}\text { Burr Hole for SAH } \\
\text { and Drainage }\end{array}$ & $\begin{array}{c}2 \pm \\
0.7(5 \%)\end{array}$ & 0 & \\
\hline
\end{tabular}

\begin{tabular}{|c|c|c|c|}
\hline MP Grade & i-gel (Mean, SD) & c-LMA & P-value \\
\hline 1 & $34 \pm 12.7(85.0 \%)$ & $29 \pm 11.4(72.5 \%)$ & \multirow{2}{*}{0.531} \\
\cline { 1 - 3 } 2 & $6 \pm 2.2(15.0 \%)$ & $11 \pm 2.7(27.5 \%)$ & \\
\hline \multicolumn{4}{|c|}{ Table 3. MP Grading } \\
\hline
\end{tabular}

\begin{tabular}{|c|c|c|c|}
\hline $\begin{array}{c}\text { Duration of } \\
\text { Insertion }\end{array}$ & i-gel & c-LMA & P-value \\
\hline (Seconds) & Median & Median & \multirow{2}{*}{0.001} \\
\hline & $\begin{array}{c}5.0( \\
5.0 \text { to } 6.0)\end{array}$ & $\begin{array}{c}23.0 \\
(10.5-26.5)\end{array}$ & \\
\hline \multicolumn{4}{|c|}{ Table 4. Duration of Insertion } \\
\hline
\end{tabular}

\begin{tabular}{|c|c|c|c|}
\hline Attempts & i-gel & c-LMA & P-value \\
\cline { 1 - 3 } 1 & $37 \pm 9.4(92.5 \%)$ & $32 \pm 8.7(80 \%)$ & \multirow{2}{*}{0.027} \\
\cline { 1 - 3 } 2 & $3 \pm 1.9(7.5 \%)$ & $7 \pm 2.2(17.5 \%)$ & \\
\cline { 1 - 3 } 3 & 0 & $1 \pm 0.3(2.5 \%)$ & \\
\hline \multicolumn{2}{|c|}{ Table 5. Number of Attempts taken to Insert Device } \\
\hline
\end{tabular}

\begin{tabular}{|c|c|c|c|}
\hline Complications & i-gel (n=40) & $\begin{array}{c}\text { c-LMA } \\
\text { (n=40) }\end{array}$ & P-value* \\
\hline Sore throat & $0(0.0 \%)$ & $2 \pm 0.6(5 \%)$ & 0.026 \\
\hline Dysphagia & $0(0.0 \%)$ & $0(0.0 \%)$ & 0.00 \\
\hline Dysphonia & $0(0.0 \%)$ & $1 \pm 0.3(2.5 \%)$ & 0.211 \\
\hline Earache & $0(0.0 \%)$ & $0(0.0 \%)$ & 0.00 \\
\hline Nausea & $0(0.0 \%)$ & $0(0.0 \%)$ & 0.00 \\
\hline Vomiting & $0(0.0 \%)$ & $0(0.0 \%)$ & 0.00 \\
\hline \multicolumn{4}{|l|}{ Table 6. Post-Operative Complications } \\
\hline
\end{tabular}

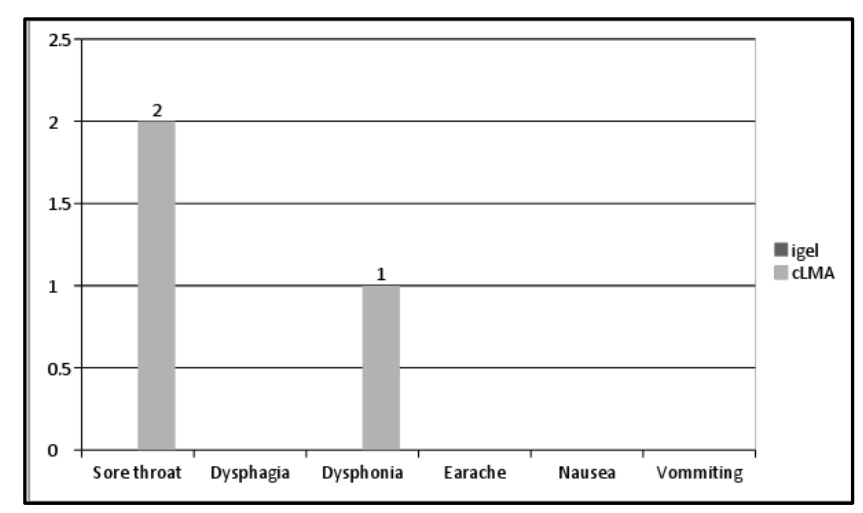

Bar Diagram (No. 1) showing Post-Operative Complications

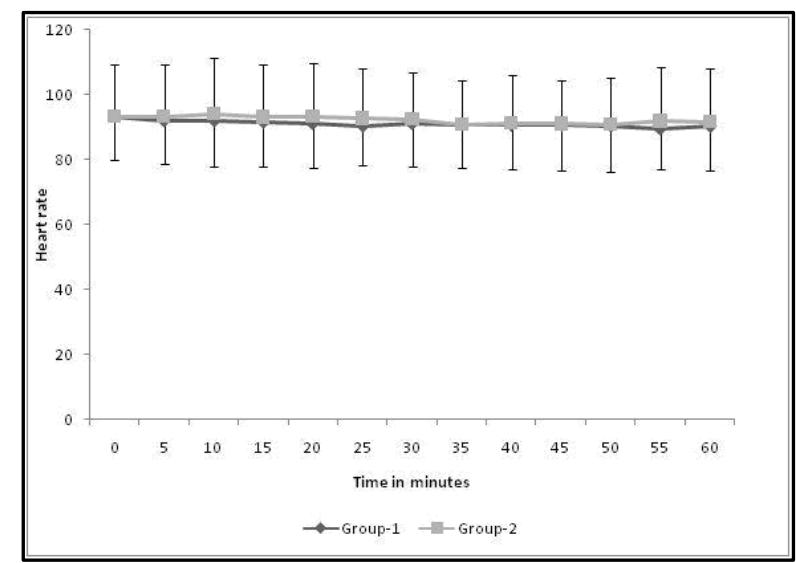

Line Diagram 1. Changes in Heart Rate

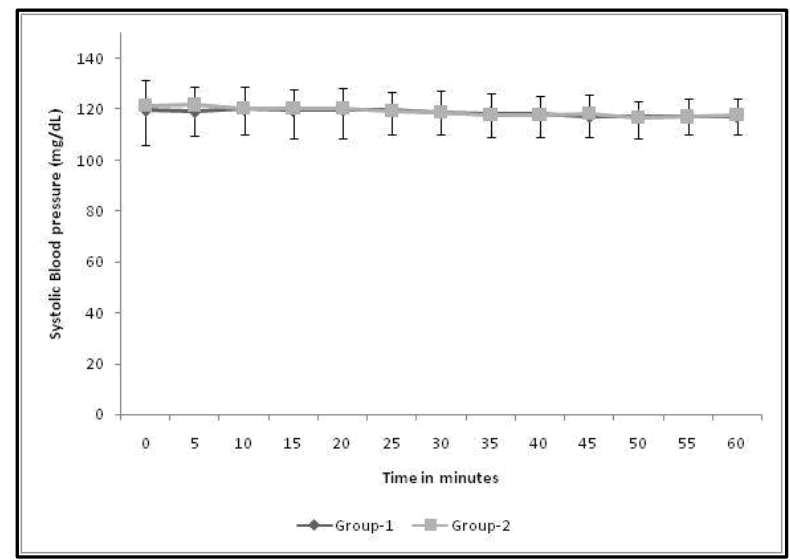

Line Diagram 2. Changes in Systolic Blood Pressure

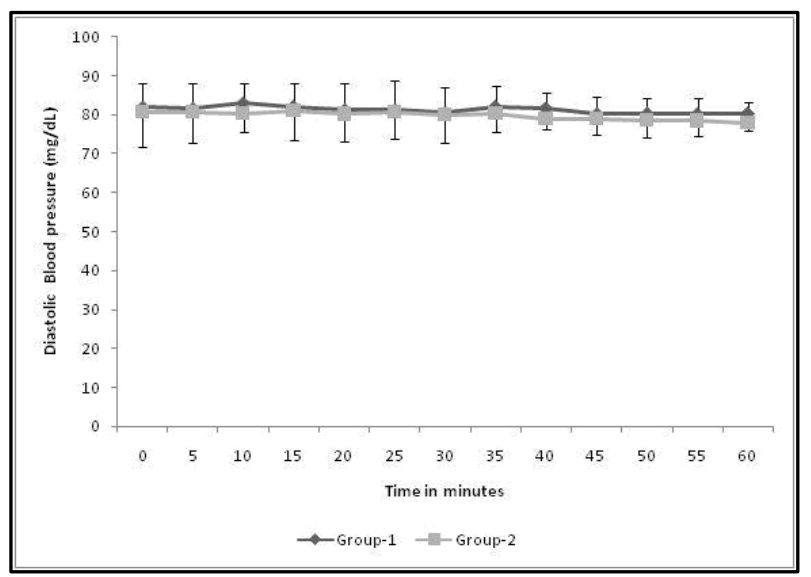

Line Diagram 3. Changes in Diastolic Blood Pressure

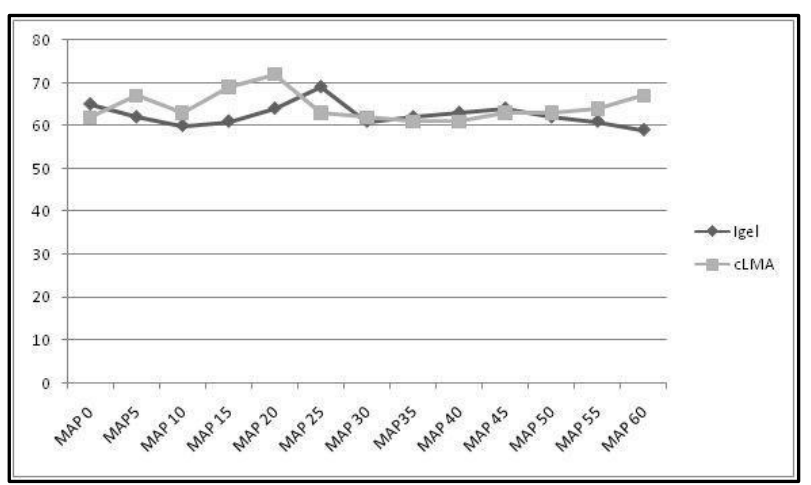

Line Diagram 4. Changes in Mean Blood Pressure 


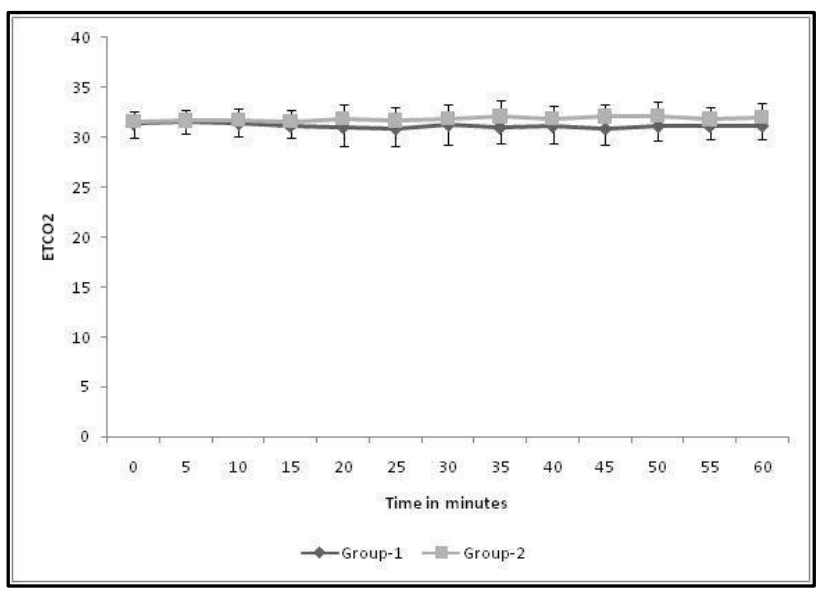

Line Diagram 5. Changes in etCO2

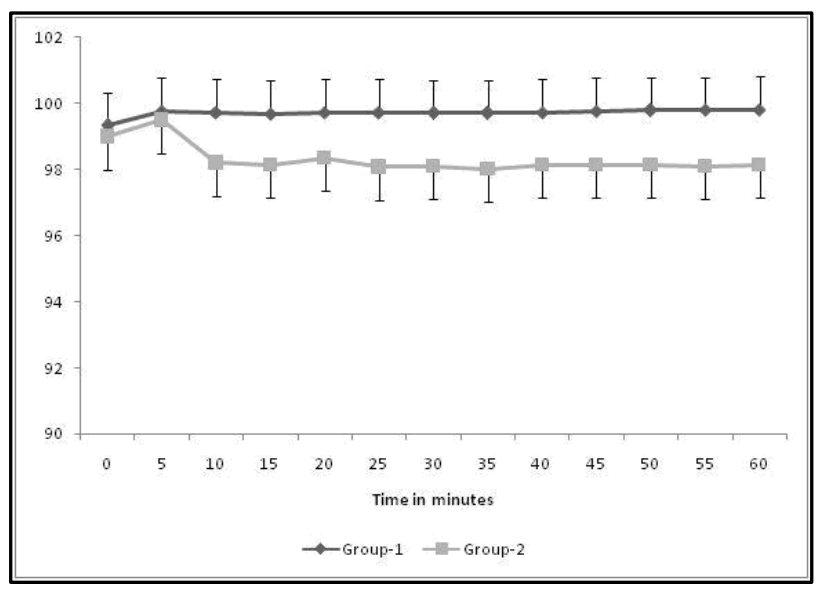

Line Diagram 6. Changes in SpO2

\section{DISCUSSION AND ANALYSIS}

Of the total 80 cases, 40 were studied for classic LMA and 40 for the i-gel over a period of one and a half years. In the c-LMA group, 23 were females and 17 were males. In the i-gel group, 18 were females and 22 were males. The age spectrum in both the LMA group and the i-gel group was from 20 yrs. to $60 \mathrm{yrs}$. The modal value for the i-gel was 38 yrs. and for -LMA was 27 yrs. This was found to be of no statistical significance with ' $p$ values' of 0.528 and 0.263 respectively for age and gender variation. Hence, the patient groups receiving i-gel and c-LMA respectively were comparable across all age groups and did not have any sampling bias in this study with respect to age and gender (Table 1).

Patients were also assessed on the basis of their BMI for both the groups. In the LMA group, the BMI varied from 21 $\mathrm{kg} / \mathrm{m} 2$ to $35 \mathrm{~kg} / \mathrm{m} 2$ (mean 23) and in the i-gel group from 17 $\mathrm{kg} / \mathrm{m} 2$ to $30 \mathrm{~kg} / \mathrm{m} 2$ (mean 29). The modal value for the BMI in the i-gel group was $18 \mathrm{~kg} / \mathrm{m} 2$ and for the c-LMA was $22 \mathrm{~kg} / \mathrm{m} 2$ and was of no statistical significance.

The list of surgeries that were undertaken for the study was also stratified between the two groups. The c-LMA was used in 3 minor eye procedures, 13 hernioplasties, 15 Open Reduction and Internal Fixation (ORIF) with tension band wiring, 7 incision and drainages and 5 excisions of fibroadenoma of the breast (Table 2).

On the contrary the i-gel was used in 3 minor eye procedures, 15 hernioplasties, 10 ORIF with tension band wiring, 7 incision and drainages and 5 fibroadenoma excisions. i-gel was also used once in a patient with sub-dural haematoma requiring drainage.

All the surgeries lasted for less than two hours. There were no intraoperative surgical complications and anaesthesia was administered as planned for the study groups. On applying the statistical tests for the type of surgeries, the p-value was found to be insignificant (0.822).

The American Society of Anesthesiologists have devised a grading system to assess the severity of illness of the patients being undertaken for surgery. The ASA physical status classification system has six well-defined classes. Out of these, as previously discussed under materials and methods patients belonging to only ASA class 1 and 2 were considered for the study. For the c-LMA group, 29 belonged to ASA grade 1 and 11 belonged to ASA grade 2. For the i-gel group, 34 belonged to ASA 1 and 6 belonged to ASA 2. It was found that the difference in the frequency of different ASA grades between the c-LMA and i-gel group had no statistical significance as the ' $p$ ' value was 0.172 .

As a part of the airway assessment tools, the Mallampati scores of all the patients were recorded. According to the design of the study, only MP grade 1 and 2 were included in the study. In the c-LMA group, 29 patients had MP grade 1 and 11 patients had MP grade 2. In the i-gel group, 34 patients had MP grade 1 and 6 patients had MP grade 2 . The difference in the MP grades between both the groups was found to be statistically insignificant with a ' $p$ ' value of 0.531 (Table 3 ).

The SADs which have been included in this study were devices which required a skilled operator to place them into the patient's oropharynx. The ease with which one is able to insert the device and place it at the intended location in a correct manner requires minimal skill. Besides after routine use, even an unskilled practitioner is expected to use it comfortably with minimal failures and untoward effects. The following figure demonstrates the correct way of inserting an LMA classic, which is also applicable for the i-gel.

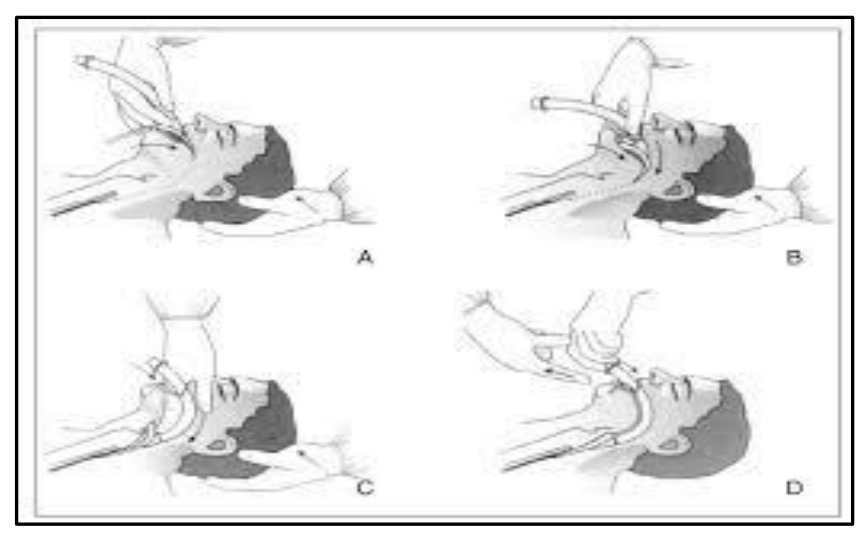

In case of c-LMA this being a cuffed device after insertion and placement into the designated slot in the oropharynx, the cuff needs to be inflated to a certain pressure. The i-gel being an uncuffed device does not require inflation. The ease by which a skilled person is able to insert an SAD is judged by the time taken for inserting the device and the number of attempts needed to achieve the patent airway. In the patients having undergone insertion of the c-LMA, the median duration of insertion was 23 seconds. For the patients belonging to the igel group the median duration was much lesser, it being 5 seconds. The median range of time taken by the c-LMA group was 10.5 - 26.5 seconds, whereas the median range of time 
taken by the i-gel group was 5 - 6 seconds. On applying the required statistical tests, the ' $p$ ' value was found to be of significance, it being 0.001 (Table 4).

While comparing two SADs, the attempts taken to insert a given SAD in a patient are also a tool for assessing the ease of insertion of that device and it contributes to the judgment regarding the better device.

In the c-LMA group, out of the 40 patients there were 32 in whom the device was successfully inserted and rightly placed in the first attempt. A second attempt at insertion was required in 7 patients in whom the correct placement could not be achieved during the first attempt, which was assessed by the absence of an adequate chest lift on ventilation using the bag after the insertion, five point auscultation of the chest for breath sounds and monitoring of the EtCO2 and the SpO2. There was only one patient where a third attempt was made for insertion and placement after two failed attempts at it (Table 5).

In the i-gel group out of the total of 40 patients the device was successfully inserted and appropriately placed in 37 patients in the first attempt, whereas 3 patients required reinsertion of the device despite attempting various listed manoeuvres (Chandy, Bailey) for ensuring correct placements. In these three patients, the i-gel was not properly placed and had to be repositioned after complete removal. Third attempt was not required in any of the patients.

The total number of attempts for ensuring safe and patent airway in 40 patients in case of c-LMA group was $(32 * 1+7 * 2+$ $1 * 3) 49$, whereas the same in case of 40 patients in the i-gel group was $\left(37^{*} 1+3 * 2\right) 43$.

The difference in the two values is statistically significant and the ' $p$ ' value was calculated using the required statistical tests and it was found to be $2.7 \%(\mathrm{p}=0.027)$.

In both the study groups (c-LMA and i-gel), the recordings were made for baseline heart rate, systolic blood pressure, diastolic blood pressure and the mean arterial pressure for all the patients.

The heart rate was measured using the ECG recording of the R-R intervals shown in the multi-parameter monitor attached to the patient. Though continuous monitoring was done for the study purposes the heart rates at time intervals of 5 minutes were recorded and immediately following the insertion and placement of the device. The mean heart rate in the c-LMA group was 93.1 per minute, whereas in the i-gel group it was 93.25 per minute. The difference in the values was found to be statistically insignificant with a 'p value' of 0.705 . Hence, there was no significant difference in the changes in the heart rate brought about by insertion of the i-gel or the c-LMA (Line Diag. 1).

The systolic blood pressure was measured by attaching a cuff in the right upper arm of every patient. The cuff covered $40 \%$ of the arm surface area and underwent timed inflations to give 5 minutes systolic and diastolic blood pressure recordings.

The mean systolic pressure (SBP) in the c-LMA group was found to be $121.6 \mathrm{mmHg}$, whereas it was $119.65 \mathrm{mmHg}$ in the i-gel group. The difference between the two values was found to be statistically insignificant with a 'p value' of 0.769 (Line Diag. 2).

The mean diastolic blood pressure (DBP) for the c-LMA group was $80.8 \mathrm{mmHg}$ and the same for the i-gel group was $82.15 \mathrm{mmHg}$. The difference between the values of the mean diastolic pressure in both the groups was again found to be of no statistical significance with a 'p value' of 0.229 (Line Diag. 3).

The mean arterial pressure (MAP) was also calculated using the standard formulae for all the patients in both the groups. Mean of the MAP for all the patients in the c-LMA group was $60.25 \mathrm{mmHg}$ and the same for the i-gel group was $62.65 \mathrm{mmHg}$. The difference between these two values was again found to be of no statistical significance and the ' $p$ value' for MAP was 0.749 (Line Diag. 4).

The end tidal carbon dioxide measurement is considered as a gold standard test for confirming tracheal intubation rather than oesophageal and also about the circulatory status of the patient. If a patient is in shock, the End tidal carbon dioxide (EtCO2) would rise. Moreover, it is used as a tool in cardiopulmonary resuscitation to assess return of spontaneous circulation. In our study as the patient was on spontaneous ventilation under anaesthesia, the EtCO2 values would help in identifying if there was any ventilatory fatigue during the surgery. It was measured using a mainstream capnometer and a reading was obtained every five minutes till the time the SAD was removed and a mean value of all the readings for each patient and the mean of all the readings of all the patients in both the groups respectively was obtained.

In the c-LMA group the mean EtCO2 was $31.55 \mathrm{mmHg}$, whereas in the i-gel group the mean EtCO2 was $31.38 \mathrm{mmHg}$. The difference between the values from the two groups was found to be statistically insignificant with a 'p value' of 0.532 (Line Diag. 5).

The SpO2 is a measure of saturation of the haemoglobin with oxygen and works on the principle of absorption spectrophotometry. This is also used as a means for assessing adequacy of ventilation. The mean SpO2 for the c-LMA group was $99 \%$ and the same for the i-gel group was $99.3 \%$. The difference in the mean values from both the groups was found to be of no statistical significance and the 'p value' for the same was calculated to be 0.843 (Line Diag. 6).

There are certain set of complications, which may occur at the time of insertion of the devices. As discussed previously, the larynx and the pharynx are richly supplied by a plexus of nerves which originate from the vagus and the glossopharyngeal nerve. The blood supply is derived from the superior and inferior thyroid arteries. The larynx is formed by a mucosa covered cartilaginous framework, which can get easily injured if the proper technique for device insertion is not applied. Such injuries can also occur incidentally. They get identified post-operatively after cessation of anaesthesia. The patients may complain of sore throat associated with post device removal cough, dysphagia which would mean pain during swallowing, dysphonia meaning difficulty in vocalising which could be due to injury to the superior, inferior or recurrent laryngeal nerve. Associated cyanosis or numbness of the tongue with earache due to blockade of the Eustachian tube can also occur. Injury to the laryngopharynx if not managed on time can also lead to life-threatening infections. Nausea and vomiting may be reported as despite the patient being on spontaneous ventilation. There could be a certain amount of gastric insufflations which would lead to distention and hence nausea followed by vomiting post-operatively. In the current study, the following post-operative complications were accounted for in both the groups (Table 6).

In the i-gel group, none of the patients reported any complications. In the c-LMA group, $5 \%$ patients reported of 
sore throat and cough post extubation which resolved within 6 hours of post-surgery recovery period. On applying the statistical tests, the ' $\mathrm{p}$ ' value was found to be significant (0.026). Dysphonia was reported in $2.5 \%$ patients with a $P$ value of 0.211 , which was insignificant. None of the patients in both the i-gel and LMA groups reported of any dysphagia, which would be characterised by difficulty in ingestion of food or swallowing, earache, nausea or vomiting.

TM Cook and C Green et al (2010) studied 8 different types of supraglottic airway devices, which included the i-gel and it was concluded that insertion of the i-gel is the easiest. ${ }^{13}$

S Ramesh and R Jayanthi (2011) conducted a study on supraglottic airway devices in children and concluded that the supraglottic airway devices are a better option since there are a number of problems associated with the face mask or the endotracheal tube. The LMA classic and the LMA ProSeal having been proven of their efficacy were replaced by an adequately sized i-gel.14

Chew EE et al (2010) compared the LMA supreme and the i-gel in spontaneously breathing ventilating patients. The comparisons were drawn over the success rate, ease of insertion and the incidence of intra- and post-op complications. Leak pressures were also compared, the same being higher for the LMA supreme than the i-gel $(25.6 \mathrm{~cm}$ of $\mathrm{H} 2 \mathrm{O}$ vs. $20.7 \mathrm{~cm}$ of H2O) and a 'p' value of 0.0001 . The ease of insertion and the attempt rate were similar for both the groups. In addition, the fibreoptic view was better for the i-gel group. ${ }^{15}$

CDT James wrote a historical note on Sir William Macewen and anaesthesia and brought to light Sir Macewen's work on the consequences of tracheal intubation leading to glottis oedema. It was useful work as the various drawbacks of tracheal intubation were brought to light. ${ }^{9}$

Rebecca Preston (2011) reviewed the role of the i-gel in resuscitation. In 2009, it was included in the resuscitation guidelines by various groups including The European Resuscitation Guidelines and The Difficult Airway Society (DAS) extubation guidelines. The review examined the published evidence of i-gel focusing on the data, which is relevant for its use. ${ }^{16}$

\section{CONCLUSION}

The following sets of conclusions are drawn here: The i-gel takes a lesser amount of time for insertion as compared to the LMA classic. The calculated mean for the i-gel being $5 \mathrm{~s}$ as compared to 23s for the LMA classic. On applying the relevant statistical tests, a P-value of 0.001 was obtained, it being highly significant.

The i-gel is easier to insert as compared to the LMA classic. Most of the i-gels were successfully inserted in the first attempt. 7 c-LMA's and 2 i-gel's required a second attempt and 1 c-LMA required a third attempt for insertion. A p-value of 0.027 was obtained, which was statistically significant.

The Heart rate, Systolic blood pressure, Diastolic blood pressure, mean arterial blood pressure, Oxygen saturation and the End tidal carbon dioxide were comparable between both the groups and there was no statistical significance of the same.

Incidence of sore throat as a post-operative complication is found to be higher in the c-LMA group as compared to the i-gel group. A p-value of 0.026 was obtained, which was found to be significant. Overall, the i-gel appears to be a better supraglottic airway device as compared to the LMA classic.

\section{REFERENCES}

[1] Durrani HD, Butt KJ, Sadaf S, et al. Comparison between LMA classic and the i-gel in anaesthetized, spontaneously breathing patients during elective surgical procedures. Anaesthesia, Pain and Intensive Care 2013;17(3):274-8.

[2] Das B, Mitra S, Samanta A, et al. Comparison of i-gel supraglottic device with classic larengeal mask airway in anaesthetized paralysed children undergoing elective surgery. Anaesthesia Essays and Researches 2012;6(2):180-3.

[3] Goyal R, Shukla RN, Kumar G. Comparison of size 2 Igel supraglottic airway with LMA-Proseal and LMA-Classic in spontaneously breathing children undergoing elective surgery. Peadiatric Anaesthesia 2012;22(4):355-9.

[4] Singh J, Yadav MK, Marhatta SB, et al. A randomized cross over comparison of the LMA classic with i-gel LMA in the management of difficult airway of post burn neck contracture patients. Indian Journal of Anaesthesia 2012;56(4):348-52.

[5] Lee JR, Kun MS, Kim JT, et al. A randomized trial comparing the i-gel ${ }^{\mathrm{TM}}$ with the classic ${ }^{\mathrm{TM}}$ LMA in children. Anaesthesia 2012;67(6):606-11.

[6] Brain AI. The development of the Laryngeal Mask - a brief history of the invention, early clinical studies and experimental work from which the Larengeal mask evolved. European Journal of Anaesthesiology Suppl 1991;4:5-17.

[7] Brain AI. The Larengeal mask airway - a possible new solution to airway problems in emergency situations. Archives of Emergency Medicine 1984;1(4):229-32.

[8] ClinicalTrials.gov. Comparison of the i-gel to the Larengeal Mask Airway. www.clinicaltrials.gov/ct2/show/NCT00706823.

[9] James CD. Sir William Macewen and anaesthesia. Anaesthesia 1974;29(6):743-53.

[10] Van Zundert AA, Fonck K, Al-Shaikh B, et al. Comparison of the LMA-classic with the new disposable seal laryngeal mask in spontaneously breathing adult patients. Anesthesiology 2003;99(5):1066-71.

[11] Drolet P. Supraglottic airways and pulmonary aspiration: the role of the drain tube. Can J Anesth 2009;56(10):715-20.

[12] Jayashree S. Laryngeal mask airway and its variants. Indian J Anaesth 2005;49(4):275-80.

[13] Cook T, Howes B. Supraglottic airway devices: recent advances. CEACCP 2011;11(2):56-61.

[14] Ramesh S, Jayanthi R. Supraglottic airway devices in children. Indian Journal of Anaesthesia 2011;55(5):47682.

[15] Nolan JP, Lockey D. Airway management for out-ofhospital cardiac arrest - more data required. Resuscitation 2009;80(12):1333-4.

[16] Preston R. The i-gel supraglottic airway - a review of its role in resuscitation. European Critical Care and Emergency Medicine 2011;3:6-8. 